SFB

Landscape pattern and car use: Linking household data with satellite imagery

Rose Keller, Colin Vance

Nr. 32/2013

$\mathcal{O}$

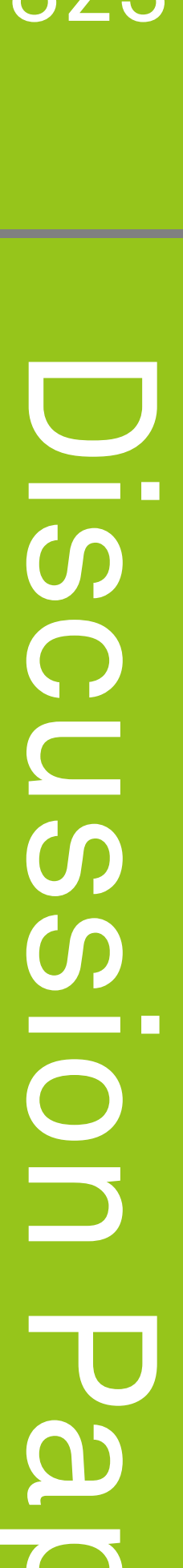

0

(1)

$(\longrightarrow)$
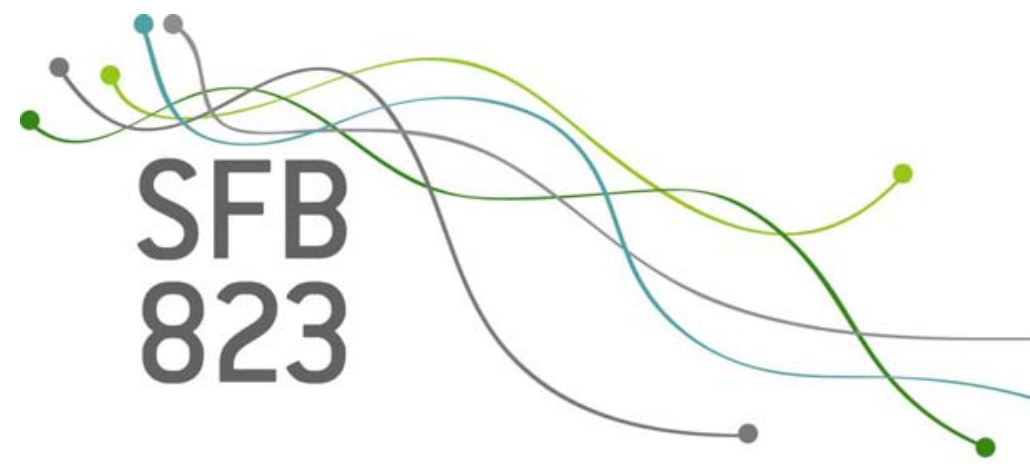



\title{
Landscape pattern and car use: Linking household data with satellite imagery
}

\author{
Rose Keller \\ Bremen International Graduate School of Social Sciences \\ Jacobs University Bremen \\ Campus Ring 1 \\ 28759 Bremen \\ Germany \\ Tel: +49 (0) 4212003962 \\ e-mail: rkeller@bigsss-bremen.de \\ Colin Vance \\ RWI and Jacobs University Bremen \\ Hohenzollernstraße 1-3 \\ 45128 Essen \\ Germany \\ Tel.: +49 (0) 2018149237 \\ e-mail: vance@rwi-essen.de
}




\begin{abstract}
:
Landscape pattern has long been hypothesized to influence automobile dependency. Because choices about land development tend to have long-lasting impacts that span over decades, understanding the magnitude of this influence is critical to the design of policies to reduce emissions and other negative externalities associated with car use. Combining household survey data from Germany with satellite imagery and other geo-referenced data sources, we undertake an econometric analysis of the relation between landscape pattern and automobile dependency. Specifically, we employ a two-part model to investigate two dimensions of car use, the discrete decision to own a car and, conditional upon ownership, the continuous decision of how far to drive. Results indicate that landscape pattern, as captured by measures of both land cover (e.g. the extent of open space and landscape diversity) and land use (e.g. the density of regional businesses) are important predictors of car ownership and use. Other policy-relevant variables, such as fuel prices and public transit infrastructure, are also identified as correlates. Based on the magnitude of our estimates, we conclude that carefully considered land development and zoning measures - ones that encourage dense development, diverse land cover and mixed land use - can have beneficial impacts in reducing car dependency that extend far into the future.
\end{abstract}

Key terms: Landscape pattern, Satellite imagery, Germany, Two-part model

Acknowledgements: The authors express their gratitude to three anonymous reviewers for their constructive comments on an earlier draft. This paper will additionally appear as: Keller, R. and C. Vance, Landscape pattern and car use: Linking household data with satellite imagery, Journal of Transport Geography (2013): 10.1016/j.jtrangeo.2013.07.006. This research was supported by the Collaborative Research Center "Statistical Modelling of Nonlinear Dynamic Processes" (SFB 823) of the German Research Foundation (DFG), within the framework of project A3, "Dynamic Technology Modelling." 


\section{INTRODUCTION}

The reduction of $\mathrm{CO}_{2}$ from transportation, which currently comprises nearly a quarter of total $\mathrm{CO}_{2}$ emissions in the European Union (EU), poses a vexing challenge in formulating policies to protect the climate. While $\mathrm{CO}_{2}$ emissions in the agricultural-, industrial- and energy sectors all fell in the EU between 1990 and 2009, those from transport increased substantially, rising by $27 \%$ over the same period (EEA 2011a). With $12 \%$ of total $\mathrm{CO}_{2}$ emissions in the EU attributed to cars alone, which are already subject to high fuel taxes and legal limits on the $\mathrm{CO}_{2}$ discharge of newly registered automobiles (Frondel et al. 2011), the question arises as to what additional measures can be availed to buck the trend of steadily increasing emissions.

Urban design, and specifically the implementation of policies that combine compact development with the provision of public transit, is often cited as a promising instrument for reducing automobile dependency. Built-up land currently covers more than a quarter of Europe's territory, leading to calls for denser development predicated on mixed land use (CEC 1990). The European Commission has long designated sprawl as a priority concern, and policy bodies in Europe have repeatedly advocated strong urban policy to steer growth around the periphery of cities and ensure denser development (CEC 1999; EEA 2006a). Nevertheless, while several studies from North America point to a mitigating influence of urban design on car ownership and use (e.g. Bento et al. 2005; Potoglou and Kanaroglou 2008; Van Acker and Witlox 2010), there have been relatively fewer studies that have investigated this linkage in the European context (some exceptions include Vance and Hedel 2008 and Buehler 2011). Given that choices about land development tend to have long-lasting impacts that span over decades, quantification of the influence of landscape pattern on car use is highly significant to the formulation of contemporary planning strategies.

Drawing on a panel of household travel data from Germany, the present paper contributes to this line of inquiry with an econometric analysis of the relationship between various dimensions of landscape pattern and automobile dependency. Germany provides an interesting case study of this topic for several reasons. First, despite having one of the highest car ownership rates in Europe, Germany has unlike its neighbors - decreased greenhouse gas emissions from transport, which dropped by 6\% between 1990 and 2009 (EEA 2011a). Second, the country has a highly heterogeneous landscape; while relatively dense urban agglomerations span across much of the west, large swaths in the east are characterized by diffuse urban 
sprawl accompanied by population decline and economic stagnation (Schmidt 2011). Finally, the German government has long been committed to reversing trends in landscape fragmentation and sprawl (Bundesminister des Innern 1985), with several German cities adopting planning guidelines that promote the spatial integration of residential, recreational and commercial land uses to reduce automobile dependency (e.g. Stadtplanungsamt 2002).

Two dimensions of dependency are considered in the present paper, the discrete choice to own a car and, conditional on ownership, the continuous choice of how far to drive. The application of a two-part model, which couples a probit and an OLS estimator, allows for an integrated treatment of these choices. A distinguishing feature of the analysis is the linkage of the survey data with satellite imagery, which affords the opportunity to construct land cover pattern metrics whose variation are hypothesized to cue varying degrees of household-level car use. Following the work of Cervero and Kockelman (1997), we are particularly interested in exploring the influence of the "3 Ds," density, diversity, and design, and to this end construct explanatory variables measuring the extent of open space, landscape diversity, and landscape fragmentation in the area of the household's location. Beyond this, our analysis includes several other correlates of car use that control for important aspects of urban design and socioeconomic context, including the density of local businesses, public transit provision, and locally prevailing fuel prices.

The remainder of the paper begins with a description of the data assembly and hypothesized effects of the explanatory variables. Section 3 discusses the modeling framework while Section 4 presents and interprets the econometric estimates. The closing section summarizes and concludes with a discussion of the benefits of expanded spatial coverage and incorporation of diverse geographic information to transportation models.

\section{DATA ASSEMBLY AND HYPOTHESIZED EFFECTS}

The main data source used in this research is drawn from the German Mobility Panel (MOP), an ongoing travel survey financed by the German Federal Ministry of Transport, Building and Housing. Participating households are surveyed for a period of one week over three consecutive years. Each year, a share of households exits the panel and is replaced by a new cohort which is in turn surveyed for three years, with the cycle continually repeating itself in overlapping waves. The information collected in the MOP includes both individual attributes such as age, gender, employment status, and mode-specific travel as well as household attributes 
such as income, car ownership, fuel prices, proximity to the nearest transit stop, and other neighborhood features. The dependent variable is derived from the survey data and is comprised of two parts, a binary indicator of whether the household owns at least one car, and a continuous variable measuring the distance driven by the household conditional on car ownership.

The data spans 14 years, from 1996 to 2009, and is limited to the car travel undertaken by households over the 5-day work week. Of these, 2,612 participated in all three years of the survey, 1,471 participated in two years, and 1,890 participated in one year, yielding a total of 12,668 observations on which the model is estimated. To correct for the non-independence of repeat observations over multiple time points in the data, the regression disturbance terms are clustered at the level of the household, and the presented measures of statistical significance are robust to this survey design feature (Deaton 1997).

The MOP has two variables that can be used to approximate the household's location, a 3-digit zip code and a county identifier, referred to in German as a Kreis. The average size of a 3-digit zip code, of which there are 671 units, is 532 square kilometers. There are 439 Kreise having an average size of 814 square kilometers. Although either of these variables could be used individually to locate the household, we found that greater spatial accuracy could be achieved by combining them. Specifically, we employed a Geographic Information System (GIS) to overlay two maps of the zip code and Kreis boundaries on top on one another, and used the polygons created by this overlay to identify the household's location. This process created a layer having a total of 1413 polygons across Germany with an average size of 253 square kilometers.

We used this map to merge in several other data sources with the MOP, two of which are available for download from the web site of the European Environmental Agency (EEA 2012a, EEA 2012b). The first of these is a European-wide coverage of satellite imagery that distinguishes 26 land cover classes and is available for the years 2000 and 2006. ${ }^{1}$ The Corine Land Cover imagery data (COordinate INformation on the Environment) is Landsat MSS raster data collected at a resolution of $100 \times 100$ meter pixel size. ArcGIS was used to calculate four variables from the imagery, each measured at the level of the polygon in which the household

\footnotetext{
1 An assessment undertaken by the European Environmental Agency (EEA 2006b) of the 2000 imagery found its thematic accuracy to be $87 \%$, thereby exceeding the target threshold of $85 \%$.
} 
is situated: the share of open space, the share of area covered by mines, dumps and construction sites, the degree of landscape fragmentation, and the degree of landscape diversity.

The share of open space, whose spatial distribution is shown in the left panel of Figure 1, is calculated by adding up the areas classified in the imagery as forest, natural vegetation, and agricultural land cover and dividing this by the area of the polygon. Contrasting with other commonly used measures of density employed in the literature, such as population per square kilometer and measures of accessibility to jobs and shops, this measure directly captures the physical configuration of land cover, a feature over which policy-makers are likely to have more direct leverage through, for example, zoning regulations. We hypothesize that households located in areas characterized by a larger share of open space are more dependent on the automobile because of the longer travel distances separating origin from destination for standard activities like shopping, recreation and work (Ewing et al 2011).

\section{FIGURE 1: Landscape pattern in Germany}
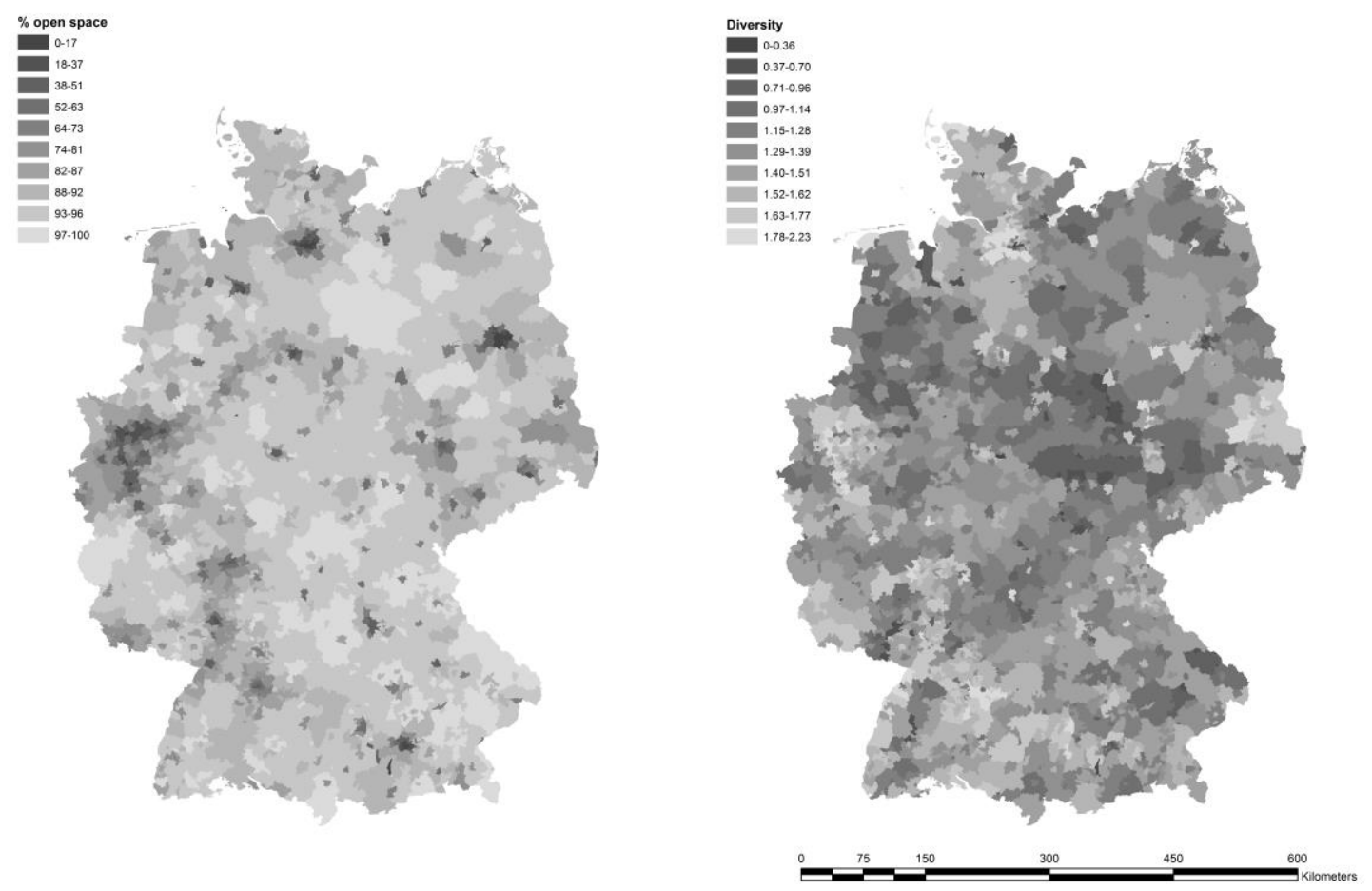

Another form of landscape configuration that is repeatedly implicated as a determinant of car use is sprawl. Travisi and colleagues (2010) investigate the relationship between sprawl and commuting using data from Italy, but otherwise little evidence on this issue exists from the European context. Recognizing that the 
meaning of sprawl is notoriously difficult to define, much less formally quantify, we employ a measure of landscape fragmentation used in ecology that can serve as a proxy for sprawl (Turner 1996). Specifically, fragmentation is measured as the inverse of the effective mesh size, a metric based on the probability that two points chosen randomly in a region are connected (EEA 2011b): effective mesh size $=\frac{1}{A_{\text {total }}} \sum_{i=1}^{n} A_{i}^{2}$. The subscript $i$ indexes each contiguous patch of land having a particular land cover classification and $A_{i}$ measures the area of the patch. $A_{\text {total }}$ gives the area of the polygon in which the household is situated. As described further in Jaeger $(2000,2002)$, the effective mesh size provides a quantitative expression of landscape connectivity, one that has been widely implemented by various European countries as an indicator for environmental monitoring (EEA 2011b). We hypothesize that this variable is positively associated with car travel, given that highly fragmented landscapes typically necessitate longer travel distances over circuitous routes.

In developing the measure of diversity, whose distribution is presented in the right panel of Figure 1, the aim was to simultaneously account for both the variety and prevalence of different land covers in the region that could influence mobility. Following the work of Cervero (1989) and others (e.g. Waddell 2002; Stead and Marshall 2001; Ewing et al 2001, 2011), we draw on an entropy-metric commonly employed in the biological sciences, referred to as Shannon's diversity index, which is based on information theory (Shannon and Weaver 1949). The index is defined as: diversity $=-\sum_{j}^{Q} p_{j} \ln p_{j}$, where $Q$ is the total number of land covers in the polygon and $p_{j}$ is the share belonging to the $j^{\text {th }}$ land cover class. To the extent that a diverse landscape is one characterized by mixed uses that reduce the need for car travel through an increased array of services and amenities, we hypothesize a negative effect of this variable.

The fourth measure obtained from the satellite imagery, the share of area covered by mines, dumps and construction sites, is calculated by summing the area under these three covers and dividing by the area of the polygon. As such sites fragment the land and are a disamenity that would discourage non-motorized travel, we expect their prevalence to increase car use.

The influence of commercial activity is captured by a measure of business incidence obtained from the data provider infas GEOdaten for the year 2001. This data set 
includes a count of the total number of businesses in a zip code across sectors, including retail, entertainment, and service establishments. We expect this variable to be associated with lower car use as close proximity to businesses would limit the need to travel long distances.

The costs of fuel, as well as the availability of alternative travel modes, are other potentially important determinants of car dependency that may be correlated with land use and whose omission from the model could consequently bias the results. It is plausible, for example, that fuel costs vary systematically between densely settled and rural areas. Three variables obtained directly from the MOP survey are included to capture these influences: the walking minutes from the home to the nearest transit stop, which is self-reported, a dummy variable indicating whether this stop is serviced by rail transit, and the real price paid for petrol. This latter variable, which is deflated using a consumer price index for the year 2000, is surveyed for every household and for each year of the data, so that it varies over both time and space (see Frondel and Vance 2011 for a detailed description of the construction of this variable). Increased walking distance to the transit stop is expected to increase car use while rail service is expected to decrease it owing to the greater speed and comfort associated with this mode. Higher fuel prices, to the extent they increase operation costs, are expected to reduce car use.

A final measure of geographical influence is defined by a dummy variable that equals one if the household is located in the east on the territory of the former German Democratic Republic. We ascribe no a priori expectation to this variable, but use it to explore the variation in car use owing to differences in development patterns between the west and the east.

Socioeconomic influences are captured by a suite of variables that measure household demographic composition and wealth. Household size is measured using four size dummies that distinguish between two, three, four, and five or more person households, with single-person households set as the base case. Employment status and the presence of children are measured by two dummies: one indicating homes with no working members and the other homes in which children under 10 years of age are present. The model also includes the household's monthly net income, as well as two dummies indicating households with two cars and with three or more cars. With the exception of the dummy for non-working households, the socioeconomic variables can be seen as demand shifters that increase car use 
The specification is completed with the inclusion of year dummies to capture macrolevel influences that affect the sample as a whole.

Table 1 presents the descriptive statistics of the dependent- and explanatory variables included in the model, including the units of measurement and the years over which the variable is observed. The descriptive statistics are presented in two columns to distinguish households sampled from the west and east of the country, which serves to illustrate the rather pronounced differences in landscape and sociodemographic features prevailing on both sides of this former political boundary. The final column presents a t-test of a difference in the means. These differences are seen to be statistically significant for all of the variables. Perhaps most striking in this regard is that, notwithstanding a slightly lower incidence of car ownership, the mileage of households in the east is, at 270 kilometers per week, $8 \%$ higher than the mileage in the west. This may partly owe to the east's lower density of development, as evidenced by the higher share of open space and the substantially lower degree of business density. The relatively depressed state of the economy in the east is also evident from the figures. Household income is some $13 \%$ lower and the share of households with no working members is six percentage points higher at $42 \%$, compared with $36 \%$ in the west. 
Table 1: Descriptive statistics

\begin{tabular}{llllll}
\hline Variable & Units & Years observed & West & East & $\begin{array}{l}\text { t-test, difference } \\
\text { in the means }\end{array}$ \\
\hline $\begin{array}{l}\text { Dependent variables } \\
\text { Car ownership }\end{array}$ & & & & 4.49 \\
$\quad$ Mileage* & Binary & $1996-2009$ & 0.841 & 0.802 & -2.81 \\
$\begin{array}{l}\text { Explanatory variables } \\
\text { Openspace }\end{array}$ & Kilometers & $1996-2009$ & 250.935 & 270.641 & -18.20 \\
Fragmentation & Percent & 2000,2006 & 71.892 & 81.869 & 29.96 \\
Diversity & Dimensionless & 2000,2006 & 0.120 & 0.045 & 10.01 \\
Mines, dumps, construction sites & Dimensionless & 2000,2006 & 1.429 & 1.361 & -10.38 \\
Business density & Percent & 2000,2006 & 0.447 & 0.708 & 14.30 \\
Minutes to transit & Businesses/km² & 2001 & 118.092 & 48.582 & -4.60 \\
Rail service & Minutes & $1996-2009$ & 5.595 & 6.106 & 4.99 \\
Fuel price & Binary & $1996-2009$ & 0.128 & 0.090 & -11.37 \\
2-person house & $€ /$ liter & $1996-2009$ & 1.019 & 1.050 & -4.27 \\
3-person house & Binary & $1996-2009$ & 0.362 & 0.410 & -4.01 \\
4-person house & Binary & $1996-2009$ & 0.141 & 0.175 & 5.61 \\
5-person house & Binary & $1996-2009$ & 0.151 & 0.106 & 4.91 \\
Children under 10 & Binary & $1996-2009$ & 0.048 & 0.024 & 7.77 \\
Non-working household & Binary & $1996-2009$ & 0.169 & 0.103 & -5.38 \\
Income & Binary & $1996-2009$ & 0.360 & 0.421 & 13.46 \\
2 Car* & 1000s $€$ & $1996-2009$ & 2.246 & 1.983 & 2.31 \\
3+ Car* & Binary & $1996-2009$ & 0.267 & 0.243 & -2.97 \\
Number of observations & Binary & $1996-2009$ & 0.041 & 0.055 & 2227 \\
\hline
\end{tabular}

* The presented means for these variables are based on the subsample of car-owning households. 


\section{MODELING APPROACH}

As seen in Table 2, roughly $16 \%$ of the households in the west and $20 \%$ in the east do not own a car and for whom the observation on distance driven is consequently recorded as zero. This feature of the data suggests conceptualizing car use as a twostage decision process comprising whether to own a car and, conditional on ownership, how far to drive. To model this process, we employ a procedure called the two-part model (2PM) that orders observations into two regimes defined by whether the household owns a car. The first stage, referred to as the selector equation, defines a dichotomous variable indicating the regime into which the observation falls:

$$
\begin{aligned}
& S^{*}=\tau^{\prime} X+\varepsilon_{1} \\
& S=1 \text { if } S^{*}>0 \text { and } S=0 \text { if } S^{*} \leq 0
\end{aligned}
$$

where $S^{*}$ is a latent variable indicating the utility from car ownership, $S$ is an indicator for car ownership status, the $X$ denote the determinants of this status, $\tau^{\prime}$ is a vector of associated parameter estimates, and $\varepsilon_{1}$ is an error term having a standard normal distribution. After estimating $\tau$ using the probit maximum likelihood method, the second stage, referred to as the outcome equation, involves estimating an OLS regression of distance traveled conditional on $S=1$ :

$$
E(Y \mid S=1, X)=\beta^{\prime} X+E\left[\varepsilon_{2} \mid Y>0, X\right]=\beta^{\prime} X
$$

where $Y$ is the dependent variable, measured here as the total kilometers driven by the household for all trip purposes over a 5-day week, and $\varepsilon_{2}$ is the error term, again assumed to be normally distributed.

Because the distribution of $Y$ has a long tail resembling that of the log-normal, we follow other authors (e.g. Axisa, Scott, and Newbold, 2012) in transforming it as a natural log. The prediction of this dependent variable then consists of two parts. The first part results from the probit model, $P(Y>0)=\Phi\left(\tau^{\prime} X\right)$, where $\Phi$ denotes the cumulative density function. The second part is the unconditional expectation, $E[Y]$, which, when $\mathrm{Y}$ is logged, is given by:

$$
E[Y]=\Phi\left(\tau^{\prime} X\right) \cdot \exp \left(\beta^{\prime} X+.5 \sigma^{2}\right)
$$


where $\sigma^{2}$ is the mean squared error of the second stage OLS regression.

The 2PM is one of several limited dependent variable models that have been availed in the literature on mobility decisions, others of which include the Tobit model (Golob and Van Wissen 1989; Johansson-Stenman 2002; Schwanen and Mokhtarian 2005) and Heckman's sample selection model (Kayser 2000; Vance and Iovanna 2007). Our selection of the $2 \mathrm{PM}$ was guided by three considerations. First, as noted by Maddala (1992: 341), the Tobit model is applicable only in cases where the underlying dependent variable can, in principle, take on negative values that are unobserved owing to censoring. This case clearly does not apply in the present example as the distance driven cannot be negative. Second, like the Heckman but unlike the Tobit, the 2PM allows different variables to affect both the discrete and continuous decisions pertaining to car ownership and use, and additionally allows the sign on variables included in both stages to differ. Finally, compared with Heckman model, the 2PM has less onerous identification requirements. Specifically, the $2 \mathrm{PM}$ does not require the specification of so-called exclusion restrictions, explanatory variables that are theoretically supported to determine the first-stage probit model of car use but not the second-stage OLS model of distance traveled.

With respect to the interpretation of the estimates from the $2 \mathrm{PM}$, which will be presented here as elasticities, some clarifications are warranted. First, unlike in linear models, the elasticities cannot be directly derived from the coefficients themselves but rather must be calculated by differentiating equation (4), yielding a unique elasticity for every observation in the data. For cases when the dependent variable is logged and the continuous variables are measured in levels, this differentiation is given by (Dow and Norton 2003):

$\frac{\partial E[Y]}{\partial X_{k}} \times \frac{X_{k}}{E[Y]}=\left[\beta_{k}+\tau_{k} \frac{\phi\left(\tau^{\prime} X\right)}{\Phi\left(\tau^{\prime} X\right)}\right] X_{k}$

where $\phi$ denotes the density function from the standard normal distribution. If the variable is a dummy, $D_{k}$, it instead makes sense to take the difference in the expected value function when the dummy is set to 1 and 0 , thereby capturing the discrete change in Y. Referring to equation (4), this yields:

$\left(E\left[Y \mid D_{k}=1\right]-E\left[Y \mid D_{k}=0\right]\right) / E[Y]$ 
The statistical significance of the elasticities is calculated using the Delta method, which yields an estimate of the standard error corresponding to the elasticity of each observation in the data.

\section{RESULTS AND INTERPRETATION}

Table 2 presents the results from the selector and outcome equations of the two-part model of car use. Columns 1 and 3 contain the coefficient estimates, whereas columns 2 and 4 contain the associated elasticities as calculated from Equations 5 and 6, averaged across all the observations used in the model of distance driven. ${ }^{2}$ In discussing the results, the focus is on the latter effects because they are more readily interpreted.

Three of the four land cover variables derived from the imagery - open space, diversity, and mines - have statistically significant elasticities whose magnitude suggest economically relevant associations with driving behavior. Consistent with expectations, a one percent increase in open space is associated with a $0.20 \%$ higher probability of owning a car and a roughly $0.42 \%$ increase in the distance driven over a five-day week. The elasticity of diversity is negative but statistically significant only in the outcome equation. A one percent increase in diversity is associated with a $0.19 \%$ decrease in driving, suggesting that landscapes characterized by mixed coverage lower automobile dependency. As expected, the share of mines, dumps, and construction sites has a positive effect but is also only statistically significant in the outcome equation, with a relatively smaller elasticity of about $0.015 \%$.

In appraising these results, it should be borne in mind that they represent mean effects that potentially mask substantial heterogeneity across the individual observations. An impression for the degree of this heterogeneity can be gleaned by plotting the magnitude of the individual elasticities, as is illustrated in the top three panels of Figure 2. These panels show the scatter of elasticities for the variables open space, landscape diversity, and mines over the horizontal axis and their associated Z-statistic on the vertical axis. The dotted horizontal lines indicate $\mathrm{Z}$ statistics of 1.96 and -1.96; points that fall beyond these bounds are statistically significant at the $5 \%$ level or higher. Below each plot, a histogram is additionally included to indicate the density distribution of the estimates. For all three variables, the range in statistically

\footnotetext{
${ }^{2}$ The code used for calculating the elasticities, written using the Stata software, is available from the authors upon request.
} 
significant estimates is seen to vary considerably, spanning 0.1 to 1.87 for open space, -0.01 to -0.56 for diversity, and 0 to 0.42 for mines, dumps and construction sites. These patterns highlight how the estimated elasticities for each of the considered variables are fundamentally dependent on the values assumed by the other explanatory variables in the model.

Turning to the land use variables, business density has the expected negative influence, decreasing both the likelihood of owing a car and the distance driven contingent on ownership. The two measures of public transit service, captured by the walking minutes from the household to the transit stop and the availability of rail service, also have the expected signs. Walking time has a statistically significant positive elasticity only in the ownership model, supporting the view that proximity to transit service be regarded as a fixed cost that only bears on the decision to own a car but not how far it is driven. The dummy indicating whether the nearest stop is serviced by rail is statistically significant only in the model of distance driven. As expected, the estimated effect is negative: households serviced by nearby rail drive $12 \%$ less than those with only bus service. Evaluated at the mean driving distance of 254 kilometers per week, this corresponds to a reduced distance driven of roughly 30 kilometers. As with the land cover variables, the lower panels of Figure 2 illustrate a high degree of heterogeneity in the individual estimates of the elasticities of the public transit variables. In the case of minutes to transit, for example, the elasticities vary from a minimum close to 0 to a maximum of just under $0.6 \%$.

The dummy capturing residence in the east has opposite signs in the selection and outcome models, decreasing the probability of car ownership while increasing the distance traveled. Although in the latter case the mean elasticity is not statistically significant, the bottom right panel of Figure 2 reveals a sizeable share of observations, about $42 \%$, whose Z-statistic crosses the threshold of 1.96 . That these households drive roughly $5 \%$ more kilometers per week than those in the West may partially reflect the higher concentration of employment centers in the more sparsely populated east and correspondingly longer commutes, one of the legacies of centralized planning prior to reunification of the country. The lower likelihood of easterners to own a car is more difficult to explain, particularly given that the model controls for the effects of household income and landscape features. One possibility is that there are higher fixed costs of owning a car in the east because of a higher incidence of crime, including car theft, with correspondingly higher insurance premiums. 


\begin{tabular}{|c|c|c|c|c|}
\hline & \multicolumn{2}{|c|}{ Probit: Car ownership $(1,0)$} & \multicolumn{2}{|c|}{ OLS: Distance driven } \\
\hline & Coefficient & Elasticity & Coefficient & Elasticity \\
\hline Openspace & $\begin{array}{l}0.012^{* *} \\
(0.001)\end{array}$ & $\begin{array}{l}0.204^{* *} \\
(0.021)\end{array}$ & $\begin{array}{l}0.004^{* *} \\
(0.001)\end{array}$ & $\begin{array}{l}0.420^{* *} \\
(0.066)\end{array}$ \\
\hline Fragmentation & $\begin{array}{l}-0.039 \\
(0.220)\end{array}$ & $\begin{array}{l}-0.002 \\
(0.009)\end{array}$ & $\begin{array}{r}0.117 \\
(0.115)\end{array}$ & $\begin{array}{r}0.011 \\
(0.014)\end{array}$ \\
\hline Diversity & $\begin{array}{l}-0.113 \\
(0.088)\end{array}$ & $\begin{array}{l}-0.045 \\
(0.035)\end{array}$ & $\begin{array}{r}-0.111^{*} \\
(0.049)\end{array}$ & $\begin{array}{r}-0.189^{*} \\
(0.080)\end{array}$ \\
\hline Mines, dumps, construction sites & $\begin{array}{r}0.006 \\
(0.021)\end{array}$ & $\begin{array}{r}0.001 \\
(0.003)\end{array}$ & $\begin{array}{l}0.030^{* *} \\
(0.010)\end{array}$ & $\begin{array}{r}0.015^{*} \\
(0.006)\end{array}$ \\
\hline Business density & $\begin{array}{c}-0.0003^{*} \\
(0.0001)\end{array}$ & $\begin{array}{r}-0.020^{*} \\
(0.009)\end{array}$ & $\begin{array}{r}-0.0002^{*} \\
(0.0001)\end{array}$ & $\begin{array}{r}-0.028^{*} \\
(0.011)\end{array}$ \\
\hline East & $\begin{array}{r}-0.158^{*} \\
(0.066)\end{array}$ & $\begin{array}{r}-0.048^{*} \\
(0.021)\end{array}$ & $\begin{array}{r}0.080^{*} \\
(0.034)\end{array}$ & $\begin{array}{r}0.049 \\
(0.041)\end{array}$ \\
\hline Minutes to transit & $\begin{array}{l}0.020^{* *} \\
(0.006)\end{array}$ & $\begin{array}{l}0.029^{* *} \\
(0.008)\end{array}$ & $\begin{array}{r}0.002 \\
(0.002)\end{array}$ & $\begin{array}{c}0.032^{*} \\
(0.016)\end{array}$ \\
\hline Rail service & $\begin{array}{r}-0.150^{*} \\
(0.067)\end{array}$ & $\begin{array}{r}-0.045^{*} \\
(0.021)\end{array}$ & $\begin{array}{r}-0.100^{* *} \\
(0.036)\end{array}$ & $\begin{array}{r}-0.124^{* *} \\
(0.038)\end{array}$ \\
\hline Fuel price & $\begin{array}{r}-0.794^{*} \\
(0.335)\end{array}$ & $\begin{array}{r}-0.237^{*} \\
(0.101)\end{array}$ & $\begin{array}{l}-0.390^{*} \\
(0.180)\end{array}$ & $\begin{array}{r}-0.558^{*} \\
(0.211)\end{array}$ \\
\hline 2-person house & $\begin{array}{l}0.529^{* *} \\
(0.058)\end{array}$ & $\begin{array}{l}0.142^{* *} \\
(0.015)\end{array}$ & $\begin{array}{l}-0.060 \\
(0.036)\end{array}$ & $\begin{array}{r}0.044 \\
(0.043)\end{array}$ \\
\hline 3-person house & $\begin{array}{l}0.678^{* *} \\
(0.101)\end{array}$ & $\begin{array}{l}0.149^{* *} \\
(0.017)\end{array}$ & $\begin{array}{l}-0.040 \\
(0.049)\end{array}$ & $\begin{array}{r}0.070 \\
(0.059)\end{array}$ \\
\hline 4-person house & $\begin{array}{l}0.940^{* *} \\
(0.168)\end{array}$ & $\begin{array}{l}0.180^{* *} \\
(0.020)\end{array}$ & $\begin{array}{l}-0.062 \\
(0.052)\end{array}$ & $\begin{array}{r}0.075 \\
(0.067)\end{array}$ \\
\hline 5-person house & $\begin{array}{l}1.037^{* *} \\
(0.340)\end{array}$ & $\begin{array}{l}0.182^{* *} \\
(0.031)\end{array}$ & $\begin{array}{l}-0.119 \\
(0.069)\end{array}$ & $\begin{array}{r}0.016 \\
(0.087)\end{array}$ \\
\hline Children under 10 & $\begin{array}{c}-0.231^{*} \\
(0.115)\end{array}$ & $\begin{array}{l}-0.073 \\
(0.040)\end{array}$ & $\begin{array}{r}0.075^{*} \\
(0.036)\end{array}$ & $\begin{array}{r}0.027 \\
(0.050)\end{array}$ \\
\hline Non-working household & $\begin{array}{r}-0.288^{* *} \\
(0.051)\end{array}$ & $\begin{array}{r}-0.082^{* *} \\
(0.014)\end{array}$ & $\begin{array}{r}-0.427^{* *} \\
(0.030)\end{array}$ & $\begin{array}{r}-0.470^{* *} \\
(0.034)\end{array}$ \\
\hline Income & $\begin{array}{l}0.826^{* *} \\
(0.046)\end{array}$ & $\begin{array}{l}0.334^{* *} \\
(0.018)\end{array}$ & $\begin{array}{l}0.210^{* *} \\
(0.019)\end{array}$ & $\begin{array}{l}0.755^{* *} \\
(0.065)\end{array}$ \\
\hline 2 Car & & & $\begin{array}{l}0.596^{* *} \\
(0.030)\end{array}$ & $\begin{array}{l}0.699^{* *} \\
(0.042)\end{array}$ \\
\hline $3+$ Car & & & $\begin{array}{l}0.851^{* *} \\
(0.054)\end{array}$ & $\begin{array}{l}1.302^{* *} \\
(0.122)\end{array}$ \\
\hline Constant & $\begin{array}{l}-0.665 \\
(0.393)\end{array}$ & & $\begin{array}{l}4.762^{* *} \\
(0.208)\end{array}$ & \\
\hline Year dummies $\chi^{2}(12)$ & $55.76^{* *}$ & & $22.41^{*}$ & \\
\hline $\begin{array}{l}\text { Log likelihood } \\
\mathrm{R}^{2}\end{array}$ & $-3,685$ & & 0.24 & \\
\hline Number of observations & 12,668 & & 10,559 & \\
\hline
\end{tabular}

Robust standard errors in parentheses; ${ }^{* *}$ and ${ }^{*}$ denotes significance at the 0.01 and 0.05 levels. 

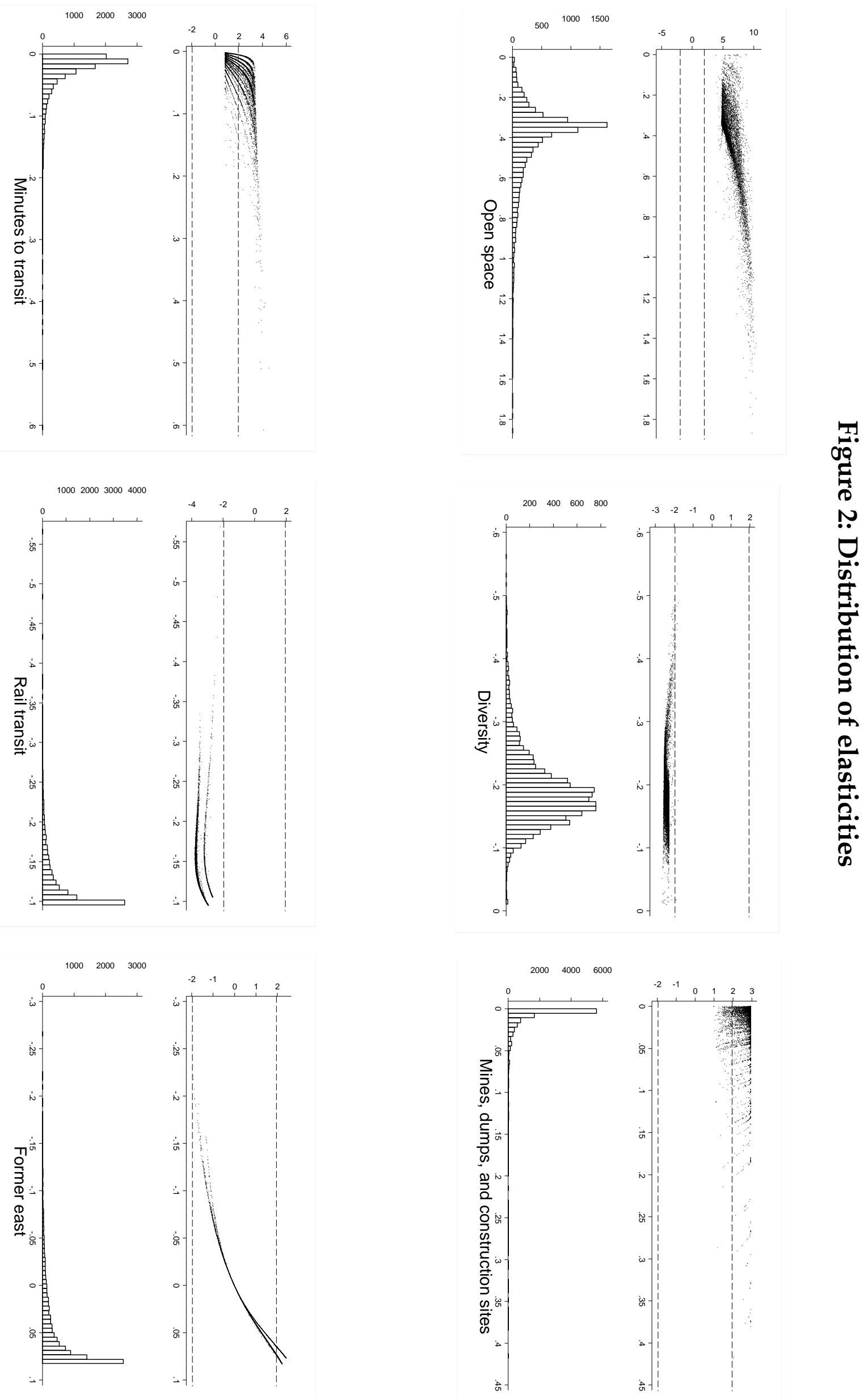
Household driving behavior is also clearly responsive to fuel prices, as evidenced by the magnitude and statistical significance of the fuel price variable. The price elasticity, at -0.56 , is of roughly the same magnitude as that obtained by Frondel and colleagues $(2008,2012,2013)$ in a series of studies from Germany using panel methods, ${ }^{3}$ but considerably higher than the estimates drawn from U.S. based studies, which typically range between less than 0.1 and 0.3 (e.g. Small and Van Dender 2007; Hughes, Knittel and Sperling 2008). One explanation for this discrepancy may be the greater array of transport alternatives and shorter trip distances in Germany than in the US, which gives German motorists greater flexibility in coping with high fuel prices. We additionally estimated models that included interaction terms to allow for differential effects of the fuel price by landscape features and socioeconomic attributes. It is plausible, for example, that households living in dense areas or those serviced by rail transit would exhibit greater sensitivity to fuel prices than remote households. The coefficients on the various interactions tested, not presented here, were uniformly statistically insignificant. This contrasts with work by Wadud Graham and Noland (2010), who find using U.S. data that the magnitude of the fuel price elasticity varies by the household's location, income, and number of vehicles owned. The absence of such differential effects in the present study has relevance for fuel taxation policy, suggesting that the distributional effects of fuel price changes in Germany are likely to be relatively uniform across income levels and geography.

The dummies for household size have the expected positive influence but are statistically significant only in the probit model of car ownership, while the hypothesized negative effect of non-working households is confirmed for both parts of the model. Referencing the final column, nonworking households are seen to drive about $47 \%$ less per week than households with at least one working member.

As with the dummy for residence in the east, the coefficients on the dummy for the presence of children under 10 have opposite signs in the two stages of the model, decreasing the probability of car ownership while increasing distance driven. The former effect is unexpected, but could be indicative of a life-cycle pattern by which young families forgo ownership of a car. The corresponding elasticities on this variable are in any case relatively small and statistically insignificant in both stages of the model.

\footnotetext{
${ }^{3}$ The data analyzed by these authors is drawn from a different sub-set of the MOP data that focuses specifically on car travel, which is recorded over a six week period during which time motorists record their mileage and the fuel price with every trip to the gas station.
} 
Among the wealth indicators, income has the expected positive effect, with a $1 \%$ increase in income corresponding to a $0.76 \%$ increase in the distance driven over the week. Finally, the dummies for two- and three-car households have positive, statistically significant, and very large effects on car mileage. Relative to one-car households, the ownership of two cars results in a roughly $70 \%$ increase in distance traveled. For three-car households the elasticity nearly doubles to $130 \%$.

\section{CONCLUSION}

Satellite imagery provides a rich source of information on landscape patterns and their evolution over time, but one that has been rarely exploited for investigating how such patterns affect transportation behavior. The use of satellite imagery in transportation research affords several advantages, among them being extensive spatial coverage at a fine grain of resolution as well as a high degree of flexibility with respect to the construction of spatial metrics and the scale of their measurement. As Ewing and colleagues (2001, 2011) note in their discussion of sampling and construct validity, landscape characteristics and boundaries are often defined by individual regions and countries that lack sufficient spatial coverage, and therefore may not precisely align in cross-regional analyses. One solution to these validity issues is improved spatial coverage by data from satellite imagery, where the land-cover classes are not already predefined per region. Additionally, researchers can combine the imagery with other GIS data sources in transportation models to move beyond the typical focus on uni-variate measures (such as distance to road or transit center) to also explore landscape pattern measures such as open space and fragmentation (Cervero 2003; Ewing and Cervero 2010).

This paper has demonstrated some of these advantages by linking satellite imagery with household survey data from Germany to explore the relationship of landscape pattern with automobile ownership and use. Based on results from a two-part model, we find that both the extent of open space and the diversity of the landscape have strong and statistically significant associations with driving behavior. Households located in regions where density is low drive more; our results suggests that a one percent increase in the share of open space increases driving by an average of $0.42 \%$ over a 5-day week. For a household that drives 254 kilometers per week, the average of the sample, this corresponds to an additional 55 kilometers over the course of a year. Conversely, households located in regions characterized by a highly diverse landscape pattern drive less. As measured by Shannon's diversity 
index, a one percent increase in this metric reduces driving by $0.19 \%$, or roughly 25 kilometers over a year. Taken together, these results suggest that urban planning decisions be made with an eye toward encouraging high density development in urban and residential zones that combine a mixture of land uses and maintenance of diverse land cover. In this regard, planners can harness the momentum of ongoing urbanization of German society through, for example, policies offering preferential tax rates on property ownership in downtown areas. According to one recent estimate in a study commissioned by the government, the share of households living in urban areas will increase on average by 1.1\% per year through to 2030 (IER, RWI, ZEW, 2010), suggesting the existence of an autonomous demand for high density residential locations.

Looking ahead, there are several possible avenues to extend on the research reported here, one of which would be to explore the robustness of the results to the scale of measurement. This could be facilitated by creating buffers of different sizes surrounding the centroid of the polygon in which the household is situated, rather than constructing the spatial variables based on the polygon, itself, as was done in the current analysis. Beyond scale, there may also be pockets of heterogeneity in the effect of the landscape variables that were undetected owing to the constraints imposed by the functional form of the econometric model. It is conceivable, for example, that the impact of density is moderated by household demographic composition and residence in the east, a possibility that could be readily tested by additional exploration using interaction terms. 


\section{REFERENCES}

Axisa, J.J., Scott, D.M. and Newbold, K.B., 2012. Factors influencing commute distance: a case study of Toronto's commuter shed. Journal of Transport Geography 24, 123-129.

Bento, A. M., Cropper, M.L., Mobarak, A.M., Vinha, K., 2005. The impact of urban spatial structure on travel demand in the United States. The Review of Economics and Statistics 87, 466-78.

Buehler, R., 2011. Determinants of mode choice: A comparison of Germany and the USA. Journal of Transport Geography 19 (4), 644-657.

Bundesminister des Innern, 1985. Bodenschutzkonzeption der Bundesregierung, Bundestags-Drucksache 10/2977 vom 7. März 1985. Stuttgart, Germany: Kohlhammer.

CEC, 1990. Green paper on the urban environment. Brussels: Commission of the European Communities.

CEC, 1999. European spatial development perspective. Brussels: Commission of the European Communities.

Cervero R., 1989. America's suburban centers: The land-use transportation link. London: Unwin Hyman.

Cervero, R., 2003. Road expansion, urban growth, and induced travel: A path analysis. Journal of the American Planning Association 69 (5), 145-163.

Cervero, R., Kockelman, K., 1997. Travel demand and the 3Ds: Density, diversity, and design. Transportation Research Part D: Transport and Environment 2 (3), 199-219.

Deaton, A., 1997. The analysis of household surveys: A microeconometric approach to development policy. Baltimore: The Johns Hopkins University Press.

Dow, W. H., Norton, E. C., 2003. Choosing between and interpreting the Heckit and two-part models for corner solutions. Health Services $\mathcal{E}$ Outcomes Research Methodology 4, 5-18.

EEA, 2006a. Urban sprawl in Europe: The ignored challenge. European Commission Joint Research Center, European Environment Agency, Report No. 10/2006.

EEA, 2006b. The thematic accuracy of Corine land cover 2000 Assessment using LUCAS (land use/cover area frame statistical survey). European Environment Agency, Report No. 7/2006.

EEA, 2011a. Laying the foundations for greener transport. European Environment Agency, Report No 7/2011.

EEA, 2011b. Landscape fragmentation in Europe. Joint EEA-FOEN Report No 2/2011. 
EEA, 2012a. Corine Land Cover Raster Database clc-2000. Version 16. Available at: $<$ http://www.eea.europa.eu/data-and-maps/data/corine-land-cover-2000clc2000-raster-4> [Accessed June 10, 2012].

EEA, 2012b. Corine Land Cover Raster Database clc-2006. Version 16. Available at: $<$ http://www.eea.europa.eu/data-and-maps/data/corine-land-cover-2006raster-2> [Accessed June 10, 2012].

Ewing, R., Cervero, R., 2010. Travel and the built environment. Journal of the American Planning Association 76 (3), 265-294.

Ewing, R., Dumbaugh, E., Brown, M., 2001. Internalizing travel by mixed land uses: Study of master-planned communities in South Florida. Transportation Research Record 1780, 115-120.

Ewing, R., Meakins, G., Bjarnson, G., Hilton, H., 2011. Transportation and land use. In: Ewing, R., Meakins, G., Bjarnson, G., Hilton, H., (Eds), Making Healthy Places. New York: Island Press, 149-169.

Frondel, M., Peters, J. Vance, C., 2008. Identifying the rebound: Evidence from a German household panel. The Energy Journal 29 (4), 154-163.

Frondel, M., Ritter, N., Vance, C. 2012. Heterogeneity in the rebound effect - Further evidence for Germany, Energy Economics 34, 461-467.

Frondel, M., Schmidt, C. M., Vance, C., 2011. A regression on climate policy - The European Commission's proposal to reduce CO2 emissions from transport. Transportation Research Part A: Policy and Practice 45, 1043-1051.

Frondel, M., Vance, C., 2011. Rarely enjoyed? A count data analysis of ridership in Germany's public transport. Transport Policy 18 (2), 425-433.

Frondel, M., Vance, C., 2013. Re-Identifying the rebound: What about asymmetry? The Energy Journal (forthcoming).

Golob, T. F., van Wissen, L., 1989. A joint household travel distance generation and car ownership model. Transportation Research B 23 (6), 471-491.

Hughes, J.E., Knittel, C.R., Sperling, D., 2008. Evidence of a shift in the short-run price elasticity of gasoline demand. The Energy Journal 29, 113-134.

IER, RWI, ZEW, 2010. Die Entwicklung der Energiemärkte bis 2030 - Energieprognose 2009. Stuttgart, Essen, Mannheim, Germany: Institut für Energiewirtschaft und rationelle Energieanwendung, Rheinisch-Westfälisches Institut für Wirtschaftsforschung, Zentrum für Europäische Wirtschaftsforschung.

Jaeger, J. A. G., 2000. Landscape division, splitting index, and effective mesh size: new measures of landscape fragmentation. Landscape Ecology 15 (2), 115-130. 
Jaeger, J. A. G., 2002. Landscape fragmentation - A transdisciplinary study according to the concept of environmental threat (in German: Landschaftszerschneidung - Eine transdisziplinäre Studie gemäß dem Konzept der Umweltgefährdung). Stuttgart, Germany: Verlag Eugen Ulmer.

Johansson-Stenman, O., 2002. Estimating individual driving distance by car and public transport use in Sweden. Applied Economics 34, 959-67.

Kayser, H. A., 2000. Gasoline demand and car choice: estimating gasoline demand using household information. Energy Economics 22 (3), 331-348.

Maddala, G. S., 1992. Introduction to Econometrics, 2nd ed. New York: MacMillan.

Potoglou, D., Kanaroglou, P. S., 2008. Modelling car ownership in urban areas: A case study of Hamilton, Canada. Journal of Transport Geography. 16 (1), 42-54.

Schmidt, S., 2011. Sprawl without growth in eastern Germany. Urban Geography 32, 105-128.

Schwanen, T., Mokhtarian, P. L., 2005. What if you live in the wrong neighborhood? The impact of residential neighborhood type dissonance on distance traveled. Transportation Research Part D 10, 127-151.

Shannon, C. E., Weaver, W., 1949. The Mathematical Theory of Communication. Urbana: University of Illinois Press.

Small, K.A., Van Dender, K., 2007. Fuel efficiency and motor vehicle travel: The declining rebound effect. Energy Journal 28, 25-52.

Stadtplanungsamt der Landeshauptstadt Dresden, 2002. Integriertes Stadtentwicklungskonzept. Dresden, Germany.

Stead, D., Marshall, S., 2001. The relationships between urban form and travel patterns: An international review and evaluation. European Journal of Transport and Infrastructure Research 1 (2), 113-141.

Travisi, C., Camagni, R., Nijkamp, P., 2010. Impacts of urban sprawl and commuting: A modelling study for Italy. Journal of Transport Geography 18 (3), 382-392.

Turner, I., 1996. Species lost in fragments of tropical rainforest: a review. Journal of Applied Ecology 33 (2), 200-209.

Van Acker, V., Witlox, F., 2010. Car ownership as a mediating variable in car travel behavior research using a structural equation modelling approach to identify its dual relationship. Journal of Transport Geography 18 (1), 65-74.

Vance, C., Hedel, R., 2008. On the link between urban form and automobile use: Evidence from German survey data. Land Economics 84, 51-65.

Vance, C., Iovanna, R., 2007. Gender and the automobile: An analysis on non-work service trips. Transportation Research Record 2013, 54-61. 
Waddell, P., 2002. UrbanSim: Modelling urban development for land use, transportation and environmental planning. Journal of the American Planning Association 68 (3), 297-314.

Wadud, Z., Graham, D.J., Noland, R.B., 2010. Gasoline demand with heterogeneity in household responses. The Energy Journal 31 (1), 47-74. 


